\title{
COMPROMETIMENTO DO ESPAÇO AÉREO NA SILICOSE AGUDA DOS JATEADORES DE AREIA: ASPECTOS NA TOMOGRAFIA COMPUTADORIZADA DE ALTA RESOLUC̣̃̃o*
}

\author{
Edson Marchiori ${ }^{1}$, Angela Ferreira ${ }^{2}$, Arthur Soares Souza Jr. ${ }^{3}$
}

Resumo Neste trabalho são apresentados os aspectos observados nas tomografias computadorizadas de alta resolução de três pacientes, todos jateadores de areia, que desenvolveram a forma aguda da silicose. Todos apresentavam, na tomografia computadorizada de alta resolução, padrão predominante de ocupação do espaço aéreo, com áreas de consolidação com broncograma aéreo, e calcificações de permeio. Além disso, foram observados nódulos em vidro fosco, com distribuição centrolobular e com tendência à confluência. Nos três pacientes foram identificados linfonodos aumentados de volume nas regiões hilares e/ou mediastinais, e calcificações linfonodais.

Unitermos: Silicose aguda. Pneumoconiose. Jateadores de areia. Tomografia computadorizada de alta resolução.

Abstract Acute silicosis airspace involvement in sandblasters: high-resolution computed tomography findings. The authors report the high-resolution computed tomography findings of three sandblaster patients with acute silicosis. High-resolution computed tomography showed air space disease in all patients, with consolidation, air bronchogram, and parenchymal calcifications. Centrilobular ground-glass nodules, generally confluent, as well as calcified mediastinal and/or hilar nodes and enlarged lymph nodes were also seen in all patients.

Key words: Acute silicosis. Pneumoconiosis. Sandblasters. High-resolution computed tomography.

\section{INTRODUÇÃO}

A silicose é uma doença pulmonar ocupacional crônica, desencadeada pela inalação de partículas de sílica cristalina, levando a uma reação tecidual de caráter fibrogênico ${ }^{(1)}$

Três tipos de doença pulmonar podem se desenvolver após exposição à sílica, dependendo do tempo de exposição e da concentração de sílica na poeira respirada ${ }^{(2)}$.

A forma clássica, crônica, em geral se desenvolve após longos períodos de ex-

* Trabalho realizado no Departamento de Radiologia da Faculdade de Medicina da Universidade Federal Fluminense (UFF), Niterói, RJ, no Serviço de Radiodiagnóstico do Hospital Universitário Clementino Fraga Filho (HUCFF) da Universidade Federal do Rio de Janeiro (UFRJ), Rio de Janeiro, RJ, e no Hospital de Base da Faculdade de Medicina de São José do Rio Preto (Famerp), São José do Rio Preto, SP.

1. Professor Titular de Radiologia da UFF, Coordenador Adjunto do Curso de Pós-graduação em Radiologia da UFRJ.

2. Professora Adjunta de Pneumologia da Faculdade de Medicina da UFF.

3. Professor Adjunto de Radiologia da Famerp, Membro do Instituto de Radiodiagnóstico Rio Preto (Ultra-X).

Endereço para correspondência: Prof. Dr. Edson Marchiori. Rua Thomaz Cameron, 438, Valparaíso. Petrópolis, RJ, 25685-120. E-mail: edmarchiori@zipmail.com.br

Recebido para publicação em 9/4/2002. Aceito, após revisão, em 10/6/2002. posição (acima de dez anos) a baixas concentrações de poeira. $\mathrm{O}$ tipo acelerado pode se desenvolver em períodos de exposição de cinco a dez anos ${ }^{(2,3)}$, sendo este um termo clínico aplicado à doença com progressão intermediária entre a forma crônica e a aguda. A forma aguda se desenvolve com um tempo de exposição relativamente curto a grandes concentrações de sílica (de meses até cerca de cinco anos), com início rápido dos sintomas clínicos e uma evolução progressiva fatal, não alterada pelo tratamento ${ }^{(4-7)}$. Clinicamente, os pacientes apresentam dispnéia de início súbito, que se torna progressiva e incapacitante. Outras queixas comuns são tosse, fadiga, febre e perda de peso ${ }^{(4)}$.

$\mathrm{O}$ interesse deste estudo prende-se ao fato da silicose aguda dificilmente ocorrer em países desenvolvidos, devido às legislações internacionais sobre o assunto, da forma aguda ser praticamente sempre letal e de, apesar disto, ainda ocorrer em nosso meio. A literatura recente é pobre em relatos desses casos, especialmente no que se refere aos achados na tomografia computadorizada de alta resolução (TCAR).

O objetivo deste trabalho foi analisar as TCAR de três pacientes com silicose aguda dos jateadores de areia, nas quais o aspecto predominante foi o comprometimento do espaço aéreo.

\section{CASUÍSTICA E MÉTODOS}

Foram estudados três pacientes, todos do sexo masculino, com idades variando de 21 a 30 anos e média de 24 anos. Eles trabalhavam como jateadores de areia, com tempos de exposição variando de dois a quatro anos. Dois deles foram acompanhados no Hospital Universitário Antônio Pedro, Niterói, RJ, e um no Hospital de Base, São José do Rio Preto, SP. Os exames foram feitos com protocolo de alta resolução e documentados com janelas para pulmão e para mediastino.

\section{RESULTADOS}

As TCAR demonstraram, em todos os pacientes, padrão de ocupação do espaço aéreo (Figuras 1, 2 e 3). As consolidações eram extensas, predominando nas regiões póstero-inferiores. Broncograma aéreo e calcificações de permeio às consolidações foram identificados nos três casos. Também foram vistos nódulos com atenuação 


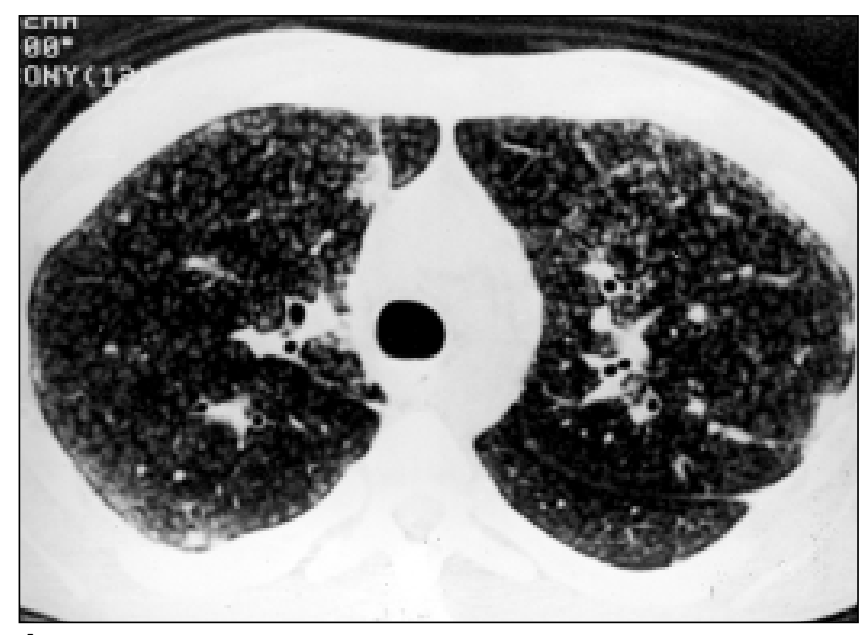

A

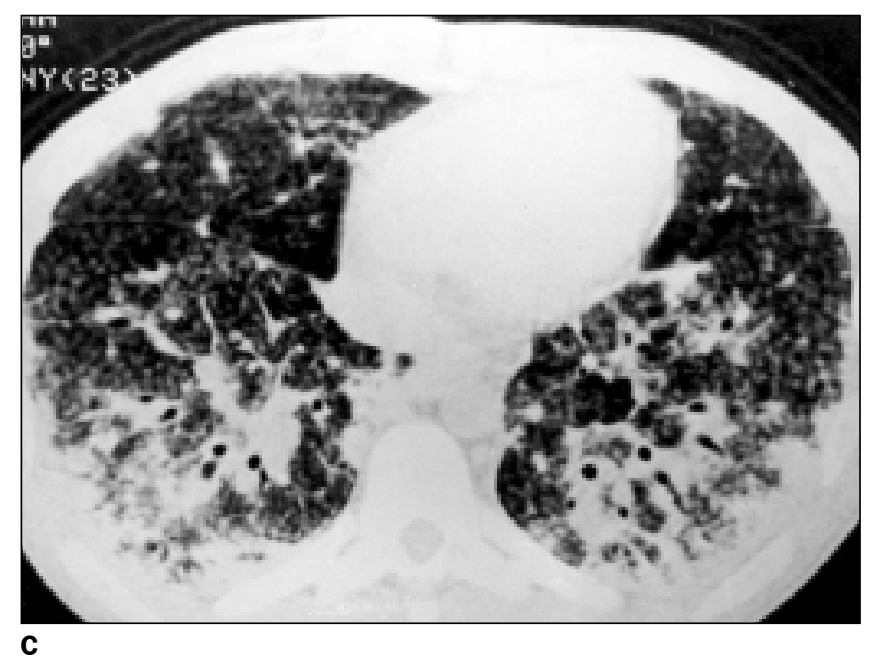

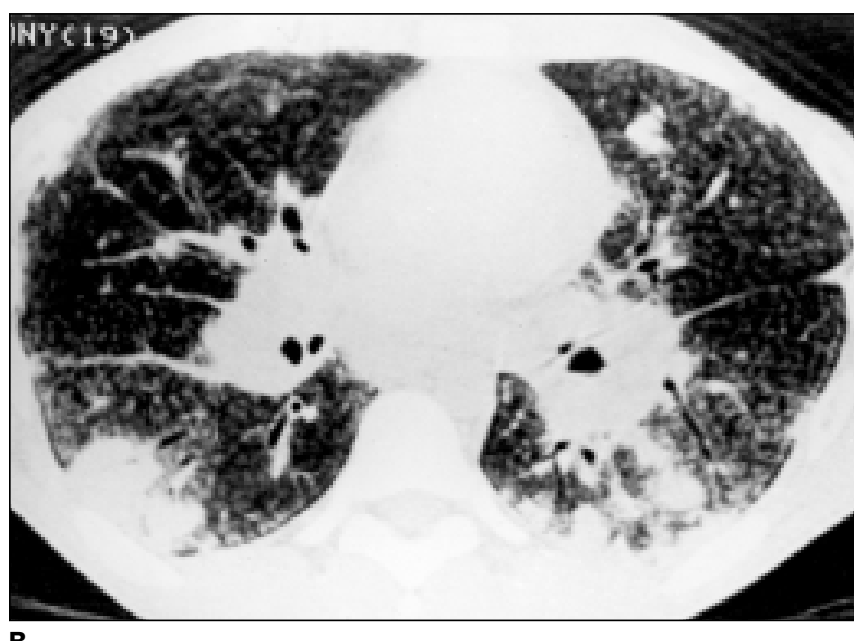

B

Figura 1. Silicose aguda. Paciente de 30 anos de idade, trabalhou com jato de areia durante quatro anos. Tomografia computadorizada de alta resolução com janela para pulmão mostrando nódulos com atenuação em vidro fosco difusos pelo parênquima pulmonar, confluentes em algumas áreas, com distribuição centrolobular. Nas regiões posteriores dos lobos inferiores observam-se também áreas de consolidação, esparsas, com broncograma aéreo. Evidenciamse, também, em B, linfonodomegalias hilares bilaterais. em vidro fosco, confluentes em algumas áreas. Nestes, não havia nenhuma alteração tomográfica que sugerisse fibrose. É importante ressaltar que os três pacientes apresentavam tanto calcificações esparsas de permeio às áreas de consolidação quanto calcificações linfonodais, com linfonodos aumentados de volume nas regiões hilares e/ou mediastinais.

\section{DISCUSSÃO}

Um padrão de silicose diferente pode ocorrer quando concentrações extremamente altas de sílica são inaladas ${ }^{(\mathbf{8})}$. A silicose aguda tem sido observada associada com padrões de agressão tissular diferentes daqueles da silicose clássica ${ }^{(6)}$. Embora alguns pacientes possam apresentar nódulos silicóticos e fibrose densa ${ }^{(6)}$, a maior parte deles apresenta um quadro anatomopatológico que lembra a protei- nose alveolar idiopática, na qual os espaços aéreos estão preenchidos por material proteináceo, rico em lipídios, eosinofílico e granular, que se cora pelo ácido periódico-reativo de Schiff (PAS) ${ }^{(\mathbf{8})}$, misturado com restos celulares ${ }^{(9)}$. O material fosfolipídico é semelhante ao surfactante pulmonar $^{(3,8)}$. Alguns autores chamam esta forma da doença de silicoproteinose ${ }^{(4)}$ ou de proteinose alveolar silicótica ${ }^{(3,8)}$. A forma intermediária entre a silicose clássica e a aguda é chamada de silicose acelerada.

Os limites entre as três formas da silicose não são nitidamente demarcados. Em um dos extremos tem-se a silicose aguda, ou silicoproteinose, com tempo muito curto de exposição (em média menor que quatro anos), com pouca ou nenhuma fibrose, com as lesões praticamente se restringindo à ocupação alveolar por material lipoproteináceo, PAS positivo. No outro extremo, a silicose clássica, com nódulos si- licóticos individualizados ou confluentes (fibrose maciça progressiva), evidências de enfisema e/ou fibrose, e tempo de exposição longo (acima de 10 ou 15 anos).

$\mathrm{Na}$ silicose dos jateadores de areia, a forma acelerada é a mais freqüentemente observada. Ela ocupa uma faixa ampla, intermediária entre as duas formas anteriores, abrangendo desde casos com tempo curto de exposição mas com predomínio de componentes anatomopatológicos (e radiológicos) da forma clássica (nódulos silicóticos e evidências de fibrose), até casos com tempo de exposição longo (acima de dez anos) mas com características morfológicas mistas, em que, ao lado das lesões da silicose clássica, observam-se também alterações que estão presentes na forma aguda da doença.

No nosso meio, o jateamento de areia é também responsável pelos raros casos de silicose aguda. Jateamento de areia é um 


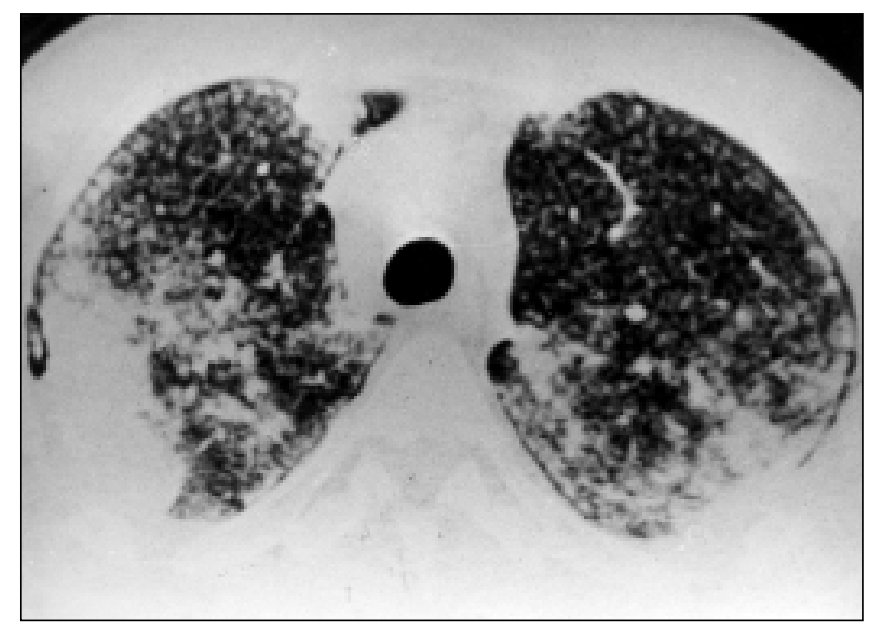

A

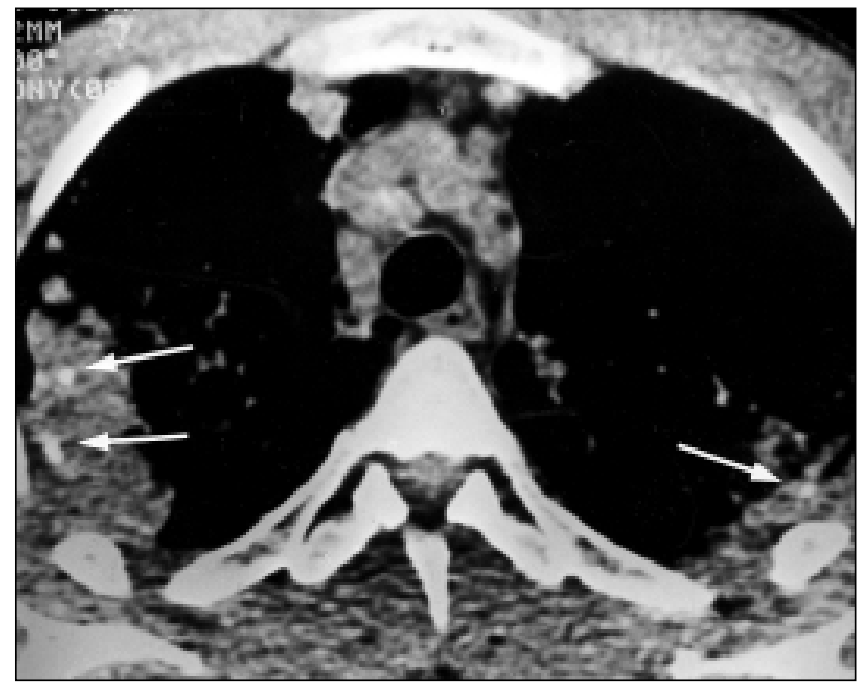

C

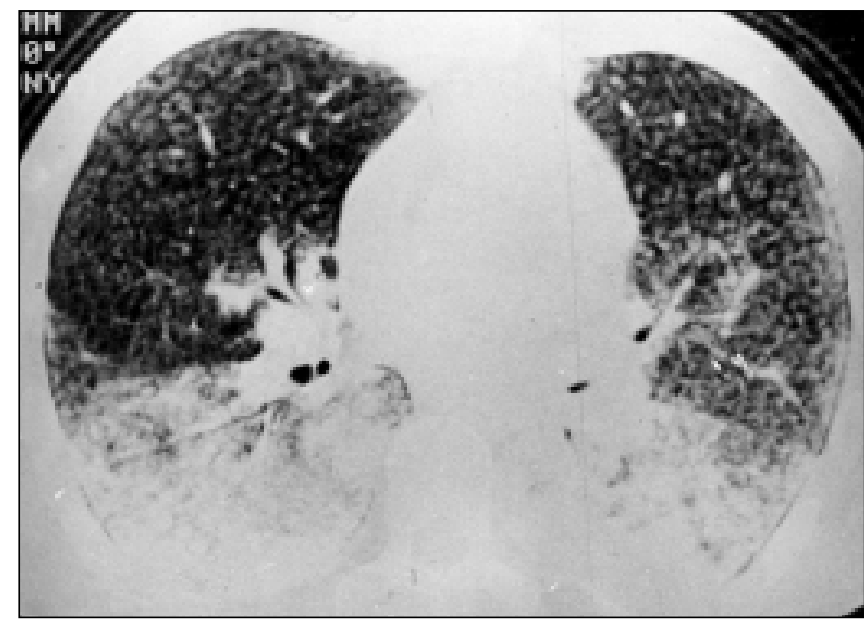

B

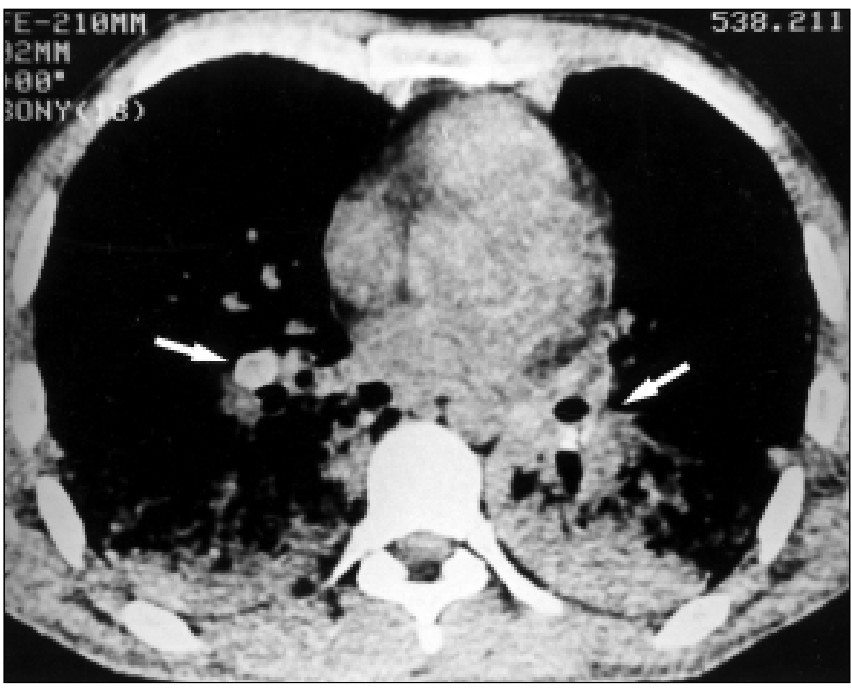

Figura 2. Silicose aguda. Paciente de 21 anos de idade, jatista de areia há três anos. Em $\mathbf{A}$ e $\mathbf{B}$, tomografia computadorizada de alta resolução com janelas para parênquima, em que se observa padrão semelhante ao caso da Figura 1, com nódulos de baixa densidade (vidro fosco) difusos pelos pulmões, com áreas de confluência, e consolidação predominando nas regiões posteriores dos lobos inferiores, com broncograma aéreo. Em C e D, janelas para mediastino, em que se observam, em C, calcificações de permeio às consolidações (setas), e em D, calcificações linfonodais (setas).

processo amplamente usado na indústria e consiste em lançar um jato de areia, sob alta pressão, numa estrutura, usualmente para polir a sua superfície ${ }^{(\mathbf{1 , 4})}$. A areia é reaproveitada até que sua ação abrasiva seja perdida pelo atrito, resultando na produção de concentrações grandemente elevadas de micropartículas de sílica livre ${ }^{(\mathbf{1})}$.

Jateamento com areia foi proibido na Inglaterra no início dos anos 50, sendo substituído por carborundum (esmeril) ou esferas de aço ${ }^{(6)}$. Na América do Norte, esta atividade foi proibida no início da década de $80^{(3)}$. Apesar da legislação contrária, também existente no Brasil (em 1992 o jateamento com areia foi proibido, por lei, no Estado do Rio de Janeiro), esta ativi- dade profissional continua a ser exercida em nosso meio, levando à morte boa parte destes trabalhadores. A silicose aguda é quase sempre fatal, com o óbito ocorrendo, na maior parte dos casos, em menos de um ano após o início dos sintomas ${ }^{(2,3,8)}$.

Radiologicamente, a silicoproteinose mostra, em geral, um padrão de ocupação do espaço aéreo, sob a forma de áreas de consolidação ou de atenuação em vidro fosco. O padrão de vidro fosco ou de opacidade difusa lembra a proteinose alveolar e reflete o achado patológico da ocupação alveolar por material lipoproteináceo. Por vezes, nódulos centrolobulares em vidro fosco são o padrão predominante ${ }^{(\mathbf{1 0})}$. Também linfonodomegalias ou cal- cificações linfonodais podem estar presentes, estando mais relacionadas a exposições maciças ${ }^{(8)}$.

É importante ressaltar que, embora histopatologicamente a silicose aguda possa ser muito semelhante à proteinose alveolar primária, na TCAR os dois quadros são bastante diferentes. Na proteinose alveolar primária encontra-se, habitualmente, aspecto de atenuação em vidro fosco difusa, com septos interlobulares espessados de permeio, originando o padrão de pavimentação em mosaico. Os outros achados comuns na silicose aguda, como nódulos centrolobulares, áreas de consolidação, calcificações parenquimatosas e linfonodais não são vistos na proteinose alveolar 

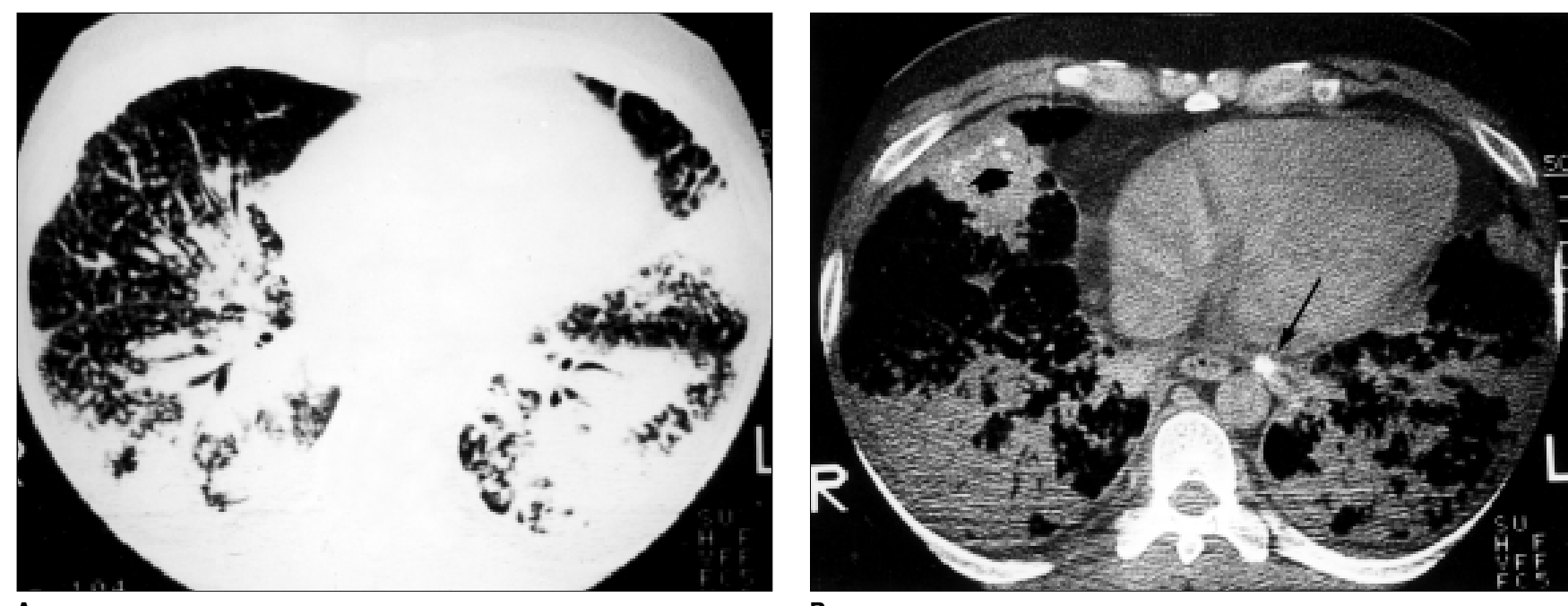

A

\section{B}

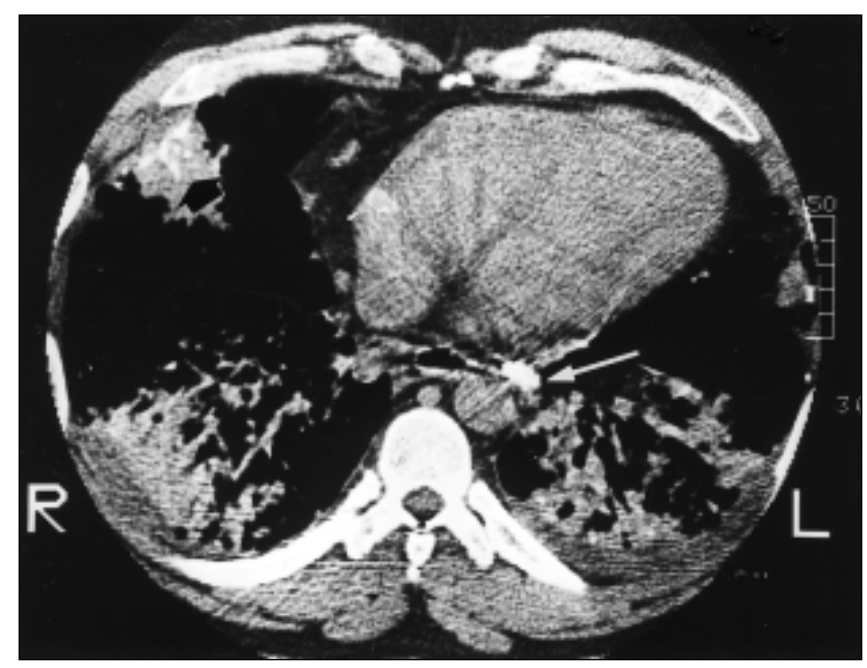

C

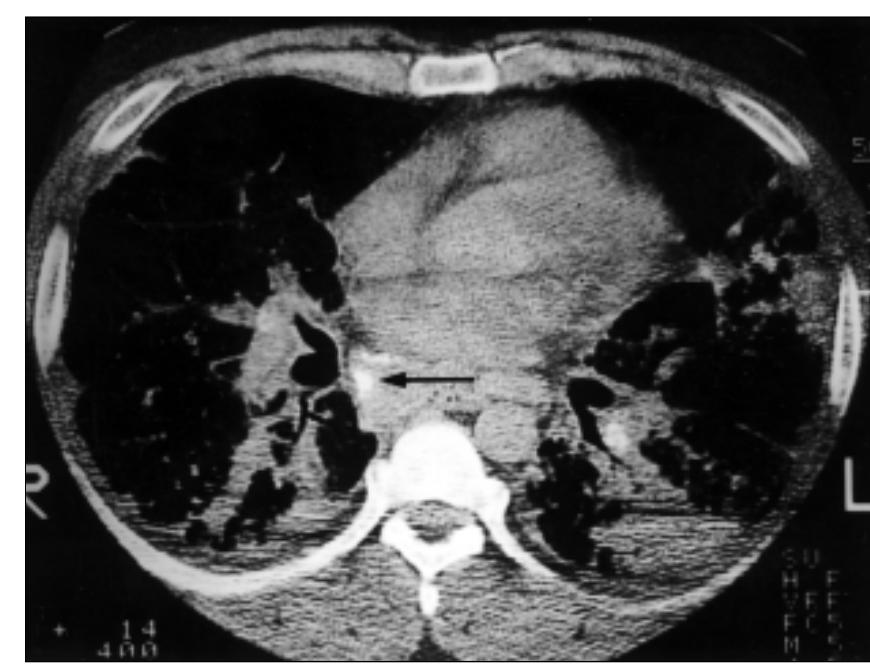

D

Figura 3. Silicose aguda. Paciente de 21 anos de idade, trabalhando há dois anos com jato de areia. Em $\mathbf{A}$, janela para parênquima pulmonar, em que se observam pequenos nódulos em ambos os pulmões, e áreas de consolidação, predominando nos campos póstero-inferiores. Em B, C e $\mathbf{D}$, janelas para mediastino, mostrando, além de extensas consolidações em ambos os pulmões, com broncograma aéreo, focos de calcificação de permeio (setas largas) e calcificações linfonodais (setas estreitas).

primária. Não encontramos, na literatura, relatos sobre este diagnóstico diferencial tomográfico.

Calcificações parenquimatosas, observadas de permeio às consolidações, foram encontradas em todos os pacientes estudados. Também não encontramos, na literatura, descrição prévia deste padrão.

\section{REFERÊNCIAS}

1. Marchiori E, Moreira DM, Luca V. Silicose aguda em ajatadores de areia. Considerações sobre 4 casos. J Pneumol 1983;9:139-43.
2. Owens MW, Kinasewitz GT, Gonzalez E. Sandblaster's lung with mycobacterial infection. Am J Med Sci 1988;295:554-7.

3. Silicosis and Silicate Disease Committee. Diseases associated with exposure to silica and nonfibrous silicate minerals. Arch Pathol Lab Med 1988;112: 673-720.

4. Buechner HA, Ansari A. Acute silico-proteinosis. A new pathologic variant of acute silicosis in sandblasters, characterized by histologic features resembling alveolar proteinosis. Dis Chest 1969; 55:274-84.

5. Xipell JM, Ham KN, Price CG, Thomas DP. Acute silicoproteinosis. Thorax 1977;32:104-11.

6. Suratt PM, Winn WC Jr, Brody AR, Bolton WK, Giles RD. Acute silicosis in tombstone sand- blasters. Am Rev Respir Dis 1977;115:521-9.

7. Ferreira A. Silicose. In: Aidê MA, Cardoso AP, Rufino R, et al., eds. Pneumologia. Aspectos práticos e atuais. Rio de Janeiro: Revinter, 2001:38390.

8. Graham WGB. Silicosis. Clin Chest Med 1992;13: 253-67.

9. Katzenstein ALA, Askin FB, Katzenstein AL, Day L (ed.), Livolsi VA. Katzenstein and Askin's Surgical pathology of non-neoplastic lung disease. 3rd ed. Philadelphia: WB Saunders, 1997.

10. Marchiori E, Ferreira A, Muller NL. Silicoproteinosis: high-resolution $\mathrm{CT}$ and histologic findings. J Thorac Imaging 2001;16:127-9. 